\title{
6 \\ Fertility patterns of the couples in the marriage cohorts
}

In this chapter, I undertake a bivariate analysis of the fertility of the complete group in the four marriage cohorts. I look at patterns of fertility and infant/young child mortality, mean (median) numbers of children according to family characteristics and parity progression ratios.

\section{Patterns of fertility and infant/young child mortality}

\section{Marriage cohort}

According to theories of why fertility declined, there would be differences in the fertility behaviour of the various marriage cohorts because couples were having their children in very different periods in Tasmanian society.

There were marked differences between the earlier cohorts and the 1890 cohort in the mean (median) numbers of children ever born (Table 6.1). Families in the 1860 and 1870 cohorts tended to be very large, with a mean of 7.84 children (median 8) for the 1860 cohort and 7.98 (median 8) for the 1870 cohort. The average number of children was somewhat lower for the 1880 cohort, with a mean of 7.06 (median 7), but fell markedly for the 1890 cohort to a mean of 5.62 (median 5). 
The 1860-70 levels of completed fertility are very similar to those for the completed fertility of couples in Utah who married about the same time, although fertility declined more slowly in Utah. Completed fertility in Utah declined from a mean of 8.11 for couples married from 1860 to 1874 to a mean of 6.44 for the 1895-1904 marriage cohorts (Mineau et al. 2002).

Table 6.1 Number of children ever born, complete group: 1860, 1870, 1880 and 1890 marriage cohorts, Tasmania

\begin{tabular}{|l|r|r|r|r|r|}
\hline Marriage cohort & 1860 & 1870 & 1880 & 1890 \\
\hline No. of children & \multicolumn{4}{|c|}{ Percentage } \\
\hline One & 5.1 & 4.6 & 2.2 & 4.7 \\
\hline Two & 3.5 & 3.9 & 4.3 & 10.0 \\
\hline Three & 5.9 & 5.7 & 8.2 & 12.9 \\
\hline Four & 3.9 & 4.6 & 8.2 & 12.9 \\
\hline Five & 7.4 & 5.3 & 13.2 & 15.7 \\
\hline Six & 9.4 & 8.1 & 8.9 & 9.1 \\
\hline Seven & 8.6 & 10.2 & 10.8 & 8.7 \\
\hline Eight & 11.7 & 10.2 & 9.4 & 8.1 \\
\hline Nine & 9.4 & 9.9 & 12.0 & 6.4 \\
\hline Ten & 11.7 & 11.7 & 9.8 & 3.2 \\
\hline Eleven & 6.6 & 9.5 & 4.8 & 4.5 \\
\hline Twelve & 6.6 & 7.8 & 3.8 & 2.1 \\
\hline Thirteen & 6.6 & 3.9 & 1.7 & 0.8 \\
\hline Fourteen & 2.0 & 2.5 & 1.2 & 0.4 \\
\hline Fifteen & 1.6 & 1.4 & 1.4 & 0.4 \\
\hline Sixteen & 0.0 & 0.7 & 0.2 & 0.2 \\
\hline Total (\%) & 100.0 & 100.0 & 100.0 & 100.0 \\
\hline Total (no.) & 256 & 283 & 417 & 529 \\
\hline Mean/median & Number of children ever born \\
\hline Mean & 7.84 & 7.98 & 7.06 & 5.62 \\
\hline Median & 8 & 8 & 7 & 5 \\
\hline & & & & \\
\hline
\end{tabular}

A relatively large proportion of couples in the 1860 and 1870 cohorts had very large families, with 35.2 per cent of the 1860 cohort and 37.5 per cent of the 1870 cohort having 10 or more children (Figure 6.1). The proportion of couples with very large families fell markedly in the 1880 cohort, to 23 per cent, and then halved in the 1890 cohort, to 
11.5 per cent. Similarly, the proportion of medium-sized families (4-6 children) increased from the 1870 to the 1880 cohorts and then to the 1890 cohort. The proportion of small families (1-3 children) remained about 14 per cent for the three earlier cohorts, but almost doubled to 27.6 per cent in the 1890 cohort. The proportion of large families (7-9 children) was about the same in the three earliest cohorts, but fell from the 1880 to the 1890 cohorts.

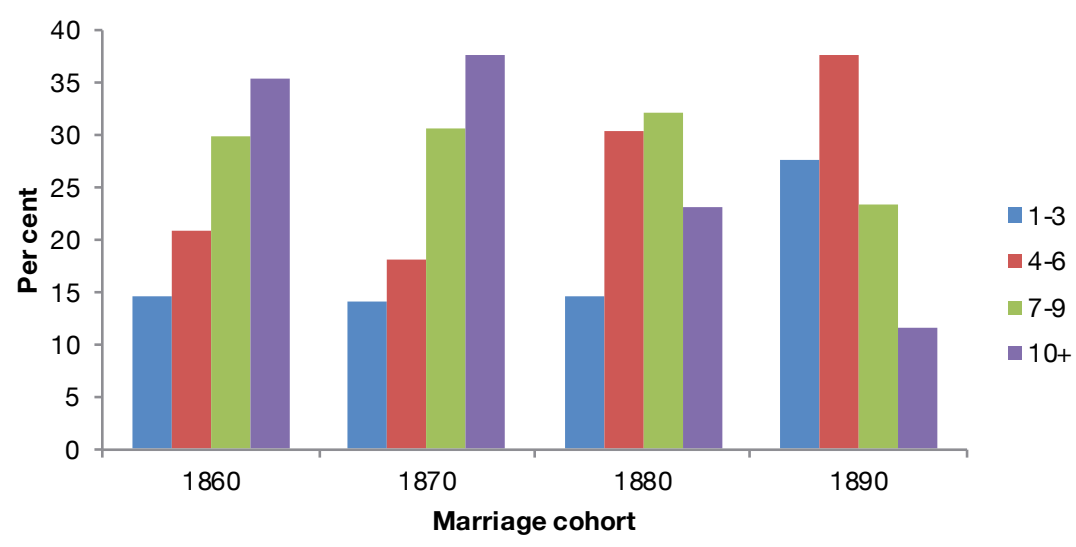

Figure 6.1 Proportions of families by number of children, complete group: 1860, 1870, 1880 and 1890 marriage cohorts, Tasmania Source: Appendix A: Table A.17 (this volume).

Thus, the fall in the mean number of children from the 1870 to the 1890 cohorts was due to a decline in the proportions of large and very large families and an increase in the proportions of small and mediumsized families. This is consistent with trends in the fertility decline for Australia as a whole (see Figure 2.5). The decline in fertility from the 1870 to the 1880 cohorts was different from the decline from the 1880 to the 1890 cohorts. The decrease in the proportion of very large families and increase in the proportion of medium-sized families began in the 1880 cohort, while the decrease in the proportion of large families and increase in the proportion of small families did not occur until the 1890 cohort. This suggests these two cohorts were stopping their childbearing at different parities. This will be investigated in the analysis of parity progression ratios. 


\section{Multiple births}

The number of children ever born to a mother is not necessarily the same as her number of pregnancies because of the incidence of multiple births. The proportions of families in the four marriage cohorts having multiple births was small, ranging from 8.6 per cent in the 1860 cohort to 4.3 per cent in the 1890 cohort (Table 6.2). The fall in the proportion of couples with multiple births is related to the fall in the proportion of large families and in the mother's age at last birth (see Table 7.3), since there are higher rates of twins at high parities and/or where mothers are older (Rao 1978). Twins made up only a tiny proportion of all pregnancies, falling from 1.3 per cent in the 1860 cohort to 0.8 per cent in the 1890 cohort.

Most multiple births were of twins, although one couple in the 1880 cohort and one in the 1890 cohort had triplets. Some families had more than one set of twins. One couple in the 1860 cohort, three in the 1870 cohort and two in the 1880 cohort had two sets of twins, while one couple in the 1860 cohort had three sets of twins.

Table 6.2 Couples with multiple births, complete group: 1860, 1870, 1880 and 1890 marriage cohorts, Tasmania

\begin{tabular}{|l|r|r|r|r|r|}
\hline Marriage cohort & 1860 & 1870 & 1880 & 1890 \\
\hline Type of family & \multicolumn{4}{|c|}{ Percentage } \\
\hline Multiple birth/s & 8.6 & 8.5 & 5.0 & 4.3 \\
\hline Singletons only & 91.4 & 91.5 & 94.7 & 95.7 \\
\hline Total (\%) & 100.0 & 100.0 & 100.0 & 100.0 \\
\hline Total (no.) & 256 & 283 & 417 & 529 \\
\hline
\end{tabular}

In all the Tasmanian marriage cohorts, couples with twins tended to have larger families than couples with singleton births only (Table 6.3). The difference between the two types of families was largest for the 1890 cohort, with families with twins having a mean of 8.13 children (median 8) and those without twins a mean of 5.51 (median 5). Fertility fell for both groups from the 1870 to the 1880 cohorts, although the fall in fertility was steeper from the 1880 to the 1890 cohorts.

A study of women born in Utah between 1807 and 1899 found that mothers with twins tended to have larger families than other mothers (Robson and Smith 2011). The authors concluded that mothers of twins had higher fecundity because of their genetic make-up (Robson and Smith 2012). 
Table 6.3 Mean and median numbers of children by singleton/multiple births, complete group: 1860, 1870, 1880 and 1890 cohorts, Tasmania

\begin{tabular}{|l|r|r|r|r|r|}
\hline Marriage cohort & 1860 & 1870 & 1880 & 1890 \\
\hline Multiple births & \multicolumn{5}{|c|}{ Mean } \\
\hline Twins in family & 9.00 & 9.50 & 9.19 & 8.13 \\
\hline Singleton only & 7.73 & 7.84 & 6.95 & 5.51 \\
\hline & \multicolumn{5}{|c|}{ Median } \\
\hline Twins in family & 8.5 & 10 & 10 & 8 \\
\hline Singleton only & 8 & 8 & 7 & 5 \\
\hline
\end{tabular}

${ }^{1}$ Means are illustrative only, because of small numbers in this group - that is, in 1860, $n=22$; in 1870, $n=24$; in 1880, $n=21$; in 1890, $n=2$.

\section{Deaths of infants and children under five years}

In Tasmania as a whole, there were large fluctuations in infant mortality for the period 1860-99, but the overall trend 'remained fairly flat' (Kippen 2002c: 65). In contrast, mortality of children aged one to 14 years fell over the same period, although there were some large annual fluctuations due to epidemics of measles and scarlet fever.

Consistent with these trends, in every marriage cohort, there were between 64 and 74 infant deaths per 1,000 births (Table 6.4). In every cohort, male infants were more likely to die than female infants-for example, in the 1860 cohort, there were 70 infant deaths per 1,000 male births compared with 56 infant deaths per 1,000 female births. The rates of young children dying aged between one and four years were smaller and fell for each subsequent marriage cohort, from 45 deaths per 1,000 children in the 1860 cohort to 22 deaths per 1,000 in the 1890 cohort.

Table 6.4 Infant and child mortality rates, complete group: 1860, 1870, 1880 and 1890 marriage cohorts, Tasmania

\begin{tabular}{|l|r|r|r|r|}
\hline Marriage cohort & 1860 & 1870 & 1880 & 1890 \\
\hline Type of death & \multicolumn{4}{|c|}{ Per 1,000 } \\
\hline Infant deaths (<1 year) & 64 & 70 & 74 & 64 \\
\hline Child deaths (1-4 years) & 45 & 40 & 30 & 22 \\
\hline Total births (no.) & 2,008 & 2,259 & 2,946 & 2,974 \\
\hline
\end{tabular}

Note: Rates for infant deaths are calculated per 1,000 live births; for child deaths, per 1,000 children reaching age one. 
The proportion of births where children died in infancy was lower for the 1860 cohort than the 1870 and 1880 cohorts: 64 infant deaths per 1,000 births compared with 70 and 74, respectively. This may be due to a change in the practice of defining a birth as either a live birth or a stillbirth, as discussed in Chapter 4.

While the trends in infant mortality for the complete group are consistent with the trends for Tasmania overall, the infant mortality rates are lower. The Tasmanian infant mortality rates 'ranged from 90 to 140 deaths per 1,000 male births, and 70 to 140 deaths per 1,000 female births' for the period 1860-99 (Kippen 2002c: 65). However, it is important to note that births to the complete group accounted for only a proportion of Tasmanian births-that is, total registered births to the complete group made up an estimated 50-60 per cent of all registered births in Tasmania in any year.

It is likely infant mortality rates for couples in which both partners survived the wife's childbearing years were lower than for other groups giving birth in the same period, possibly because these families were healthier. Infant mortality rates for the incomplete group were higher than for the complete group in every marriage cohort and for the unobserved group in the first two marriage cohorts (Appendix A: Tables A.18, A.19). A study of maternal and infant mortality in New York State in the 1930s found infants were 5.5 times as likely to die within the first month of life when their mother died in childbirth (Yerushalmy et al. 1940). In 19th-century New South Wales and Victoria, infant mortality rates for ex-nuptial children were markedly higher than for children born in wedlock over the period (NSW 1904a; Swain and Howe 1995).

Although the proportion of infants and young children who died was relatively small, the proportion of families who experienced the death of an infant and/or young child was much higher. In the 1860 cohort, half of all couples experienced the death of an infant and/or young child, with 34.8 per cent experiencing the death of an infant and 25 per cent the death of a young child (Table 6.5). The proportion of families experiencing the death of an infant and/or young child fell markedly in subsequent marriage cohorts, from 51.6 per cent for the 1860 cohort to 34.4 per cent for the 1890 cohort. This was mainly due to a fall in the proportion of couples experiencing the death of a young child. 
Table 6.5 Proportion of families with at least one infant and/or child death, complete group: 1860, 1870, 1880 and 1890 marriage cohorts, Tasmania

\begin{tabular}{|l|r|r|r|r|}
\hline Marriage cohort & 1860 & 1870 & 1880 & 1890 \\
\hline Infant/child death in family & \multicolumn{4}{|c|}{ Percentage } \\
\hline Infant death/s (<1 year) & 34.8 & 34.6 & 33.6 & 26.7 \\
\hline Child death/s (1-4 years) & 25.0 & 24.7 & 17.5 & 11.2 \\
\hline Infant and/or child death/s (<5 years) & 51.6 & 49.5 & 45.3 & 34.4 \\
\hline Total families (no.) & 256 & 283 & 417 & 529 \\
\hline
\end{tabular}

Of all families who experienced the death of an infant and/or young child, most experienced only one death, with the proportion about 60 per cent for the 1860 and 1870 cohorts and increasing to 72 per cent for the 1890 cohort (Table 6.6). The proportion experiencing three or more deaths was about 15 per cent in the earliest three cohorts but fell to 7.6 per cent in the 1890 cohort. This is related to the marked fall in the number of very large families, since families with three or more deaths tended to be those with nine or more children. For instance, in the 1870 cohort, 18 of the 20 families who experienced the deaths of three or more infants and/or young children had nine or more children. This is consistent with findings about the relationship between high fertility and high infant mortality discussed in Chapter 1.

Table 6.6 Number of deaths for families experiencing at least one death of an infant and/or young child, complete group: 1860, 1870, 1880 and 1890 marriage cohorts, Tasmania

\begin{tabular}{|l|r|r|r|r|}
\hline Marriage cohort & 1860 & 1870 & 1880 & 1890 \\
\hline Number of deaths & \multicolumn{4}{|c|}{ Percentage } \\
\hline One & 61.4 & 57.9 & 66.1 & 72.0 \\
\hline Two & 23.5 & 27.9 & 18.5 & 20.3 \\
\hline Three & 9.1 & 6.4 & 9.5 & 5.5 \\
\hline Four & 3.8 & 2.9 & 3.2 & 1.6 \\
\hline Five or more & 2.3 & 5.0 & 2.7 & 0.5 \\
\hline Total (\%) & 100.0 & 100.0 & 100.0 & 100.0 \\
\hline Total families (no.) & 132 & 140 & 189 & 182 \\
\hline
\end{tabular}




\section{Children ever born}

In this section, I look at mean and median numbers of children ever born according to family characteristics that relate to the theories of fertility decline discussed in Chapter 1 or are associated with a woman's fecundity. These characteristics are: wife's age at marriage, the age difference between husbands and wives, socioeconomic status, type of geographic location, religion and literacy.

\section{Wife's age at marriage}

In examining the mean (median) number of children by women's age at marriage, because of the small numbers of women marrying at older ages, age at marriage is divided into three categories: under 20 years, 20-24 years and 25 years or older. I have used the category under 20 years for the youngest group because I wanted to look at women who married as teenagers, rather than using the category under 21 years, which refers to the group that required their parents' consent to marry.

Table 6.7 Mean and median numbers of children by mother's age at marriage, complete group: 1860, 1870, 1880 and 1890 marriage cohorts, Tasmania

\begin{tabular}{|l|r|r|r|r|r|}
\hline Marriage cohort & 1860 & 1870 & 1880 & 1890 \\
\hline Age at marriage & \multicolumn{4}{|c|}{ Mean } \\
\hline$<20$ years & 9.38 & 9.51 & 8.42 & 7.33 \\
\hline 20 to $<25$ years & 7.65 & 7.77 & 6.87 & 5.64 \\
\hline $25+$ years & 4.73 & 5.77 & 5.11 & 4.32 \\
\hline & \multicolumn{5}{|c|}{ Median } \\
\hline$<20$ years & 10 & 10 & 8 & 7 \\
\hline 20 to $<25$ years & 8 & 8 & 7 & 5 \\
\hline $25+$ years & 5 & 5 & 5 & 4 \\
\hline
\end{tabular}

Note: Excludes three women in the 1880 cohort and five in the 1890 cohort for whom age at marriage was missing.

In all marriage cohorts, women who married at younger ages had substantially higher mean (median) numbers of children than other women (Table 6.7). In the 1870 cohort, for example, the mean number of children for women marrying under the age of 20 was 9.51 (median 10), compared with a mean of 7.77 (median 8) for women 
marrying aged 20-24 years and 5.77 (median 5) for women marrying at age 25 and older. While the mean (median) number of children fell for all women across the cohorts, it fell markedly for woman marrying under 25 years of age.

\section{Age difference between husbands and wives}

The relationship between fertility and the age difference between husband and wife is affected by the wife's age at marriage, since women who are older than their husbands are likely to be older at marriage and those with much older husbands are likely to be younger at marriage. For this reason, I examine the relationship between fertility and the age difference between husbands and wives for women who married at ages 20-24 years.

Table 6.8 Mean and median numbers of children by difference in age between husbands and wives for women marrying aged 20-24 years, complete group: 1860, 1870, 1880 and 1890 marriage cohorts, Tasmania

\begin{tabular}{|l|r|r|r|r|r|}
\hline Marriage cohort & 1860 & 1870 & 1880 & 1890 \\
\hline Difference in age & \multicolumn{4}{|c|}{ Mean } \\
\hline Wife older ${ }^{1}$ & 8.62 & 7.21 & 6.80 & 5.88 \\
\hline Same age or husband 1-4 years older & 7.91 & 8.37 & 7.03 & 5.49 \\
\hline Husband 5 or more years older & 7.23 & 7.11 & 6.74 & 5.83 \\
\hline & \multicolumn{5}{|c|}{ Median } \\
\hline Wife older & 8 & 7 & 7 & 6 \\
\hline Same age or husband 1-4 years older & 8 & 9 & 7 & 5 \\
\hline Husband 5 or more years older & 7 & 7 & 7 & 5 \\
\hline
\end{tabular}

${ }^{1}$ Means for 1860 and 1870 are illustrative only because of small numbers in the groupthat is, $n=13$ for 1860 and $n=28$ for 1870 .

Note: There are three women in the 1880 cohort and five in the 1890 cohort for whom age is missing. Also excludes one couple in the 1860 cohort, two in the 1870 cohort, four in the 1880 cohort and two in the 1890 cohort for whom age of husband is missing.

There were no consistent differences in fertility across the marriage cohorts according to the age difference between husband and wife (Table 6.8). In the two earliest cohorts, couples where the husband was much older than the wife had fewer children on average than couples where the husband was the same age or one to four years older. In the 1880 cohort, couples where the wife was older than the husband or the husband was much older than the wife had fewer children on average than couples where the husband was the same age or one to four years older, although 
the differences were relatively small. In the 1890 cohort, however, couples of the same age or where the husband was one to four years older had slightly fewer children on average than other couples: they had a mean of 5.49 (median 5) children compared with a mean of 5.88 (median 6) for couples where the wife was older than the husband and 5.83 (median 5) for couples where the husband was much older than the wife.

\section{Socioeconomic status}

While fertility declined for every socioeconomic group across the four marriage cohorts, there were marked differences in the mean (and median) numbers of children according to the husband's socioeconomic status (Table 6.9). White-collar workers had the lowest mean (median) numbers of children in every marriage cohort, while farmers and unskilled workers had the highest. In the 1860 cohort, the mean number of children for white-collar workers was 6.34 (median 6) compared with a mean of 9.02 (median 9) for farmers and 8.55 (median 9) for unskilled workers. The fertility of white-collar workers in 1860 was considerably lower than fertility overall (Table 6.1). White-collar workers in the 1860 cohort may have had lower fertility because they started to restrict their fertility earlier than other groups or because they married at older ages. This will be investigated in the multivariate analysis.

There were differences in the timing of the fertility decline between the socioeconomic groups, according to falls in the mean numbers of children. Fertility fell steadily for white-collar workers over the cohorts, with the largest fall from the 1880 to the 1890 cohorts. Fertility fell for skilled workers, farmers and unskilled workers from the 1870 to the 1880 cohorts onwards, but the decline was larger for skilled and unskilled workers from the 1880 to the 1890 cohorts and for farmers from the 1870 to the 1880 cohorts. While the means are illustrative only for the two earlier cohorts, lower-skilled workers' fertility declined from the 1860 cohort onwards, with the largest decline from the 1880 to the 1890 cohorts. 
Table 6.9 Mean and median numbers of children by husband's socioeconomic status at first birth, complete group: 1860, 1870, 1880 and 1890 marriage cohorts, Tasmania

\begin{tabular}{|l|r|r|r|r|}
\hline Marriage cohort & 1860 & 1870 & 1880 & 1890 \\
\hline Occupational status & \multicolumn{4}{|c|}{ Mean } \\
\hline White-collar & 6.34 & 6.20 & 5.76 & 4.19 \\
\hline Skilled & 6.98 & 7.29 & 6.69 & 4.90 \\
\hline Farmers & 9.02 & 8.80 & 7.48 & 6.90 \\
\hline Lower-skilled ${ }^{1}$ & 7.44 & 7.05 & 7.09 & 5.35 \\
\hline Unskilled & 8.55 & 8.86 & 7.92 & 6.35 \\
\hline & \multicolumn{5}{|c|}{ Median } \\
\hline White-collar & 6 & 7 & 5 & 4 \\
\hline Skilled & 7 & 8 & 7 & 4 \\
\hline Farmers & 9 & 9 & 8 & 7 \\
\hline Lower-skilled & 8 & $7 / 8$ & 7 & 5 \\
\hline Unskilled & 9 & 10 & 8 & 6 \\
\hline
\end{tabular}

${ }^{1}$ Means are illustrative only for lower-skilled workers in 1860 and 1870 because of small numbers - that is, in 1860, $\mathrm{n}=18$ and, in 1870, $\mathrm{n}=20$.

Note: Excludes three couples in the 1860 cohort, three in the 1870 cohort and two in the 1880 cohort for whom socioeconomic status was missing.

\section{Type of geographic location}

Couples living in urban areas had fewer children on average than those living in rural areas in all marriage cohorts (Table 6.10). In the 1860 cohort, couples in urban areas had a mean of 7.24 children (median 7/8) while couples in rural areas had a mean of 8.41 (median 9). Fertility fell steadily for urban couples from the 1860 cohort, while for rural couples it began to fall from the 1870 to the 1880 cohorts. For both urban and rural couples, fertility declined more from the 1880 to the 1890 cohorts than between earlier cohorts. By the 1890 cohort, the mean number of children for couples living in urban areas had fallen to 4.74 (median 4), while the mean for rural couples had fallen to 6.25 (median 6). Although the means (medians) are illustrative only, couples who had their first birth outside Tasmania had fewer children on average than couples who had their first birth in Hobart or Launceston, except in the 1860 cohort. 
Table 6.10 Mean and median numbers of children by location at first birth, complete group: 1860, 1870, 1880 and 1890 marriage cohorts, Tasmania

\begin{tabular}{|l|r|r|r|r|r|}
\hline Marriage cohort & 1860 & 1870 & 1880 & 1890 \\
\hline Type of location & \multicolumn{5}{|c|}{ Mean } \\
\hline Urban & 7.25 & 6.81 & 6.25 & 4.74 \\
\hline Rural & 8.41 & 8.81 & 7.74 & 6.25 \\
\hline Outside Tasmania $^{1}$ & 7.24 & 6.41 & 4.89 & 4.48 \\
\hline & \multicolumn{5}{|c|}{ Median } \\
\hline Urban & $7 / 8$ & 7 & 6 & 4 \\
\hline Rural & 9 & 9 & 8 & 6 \\
\hline Outside Tasmania & 8 & 6 & 5 & 4 \\
\hline
\end{tabular}

${ }^{1}$ Means are illustrative only because of small numbers - that is, in 1860, $n=17$; in $1870, n=$ 22 ; in 1880, $\mathrm{n}=18$; and in 1890, $\mathrm{n}=27$.

As noted previously, even if couples had one birth in Tasmania, they did not necessarily have all their births in Tasmania. In every cohort except the 1880 cohort, couples who had births in Tasmania and elsewhere had more children on average than couples who had all their births in Tasmania (Table 6.11). Fertility fell from the 1870 to the 1880 cohorts onwards for couples who had some or all of their births in Tasmania, although for couples who had births in Tasmania and elsewhere the fall in fertility was larger from the 1870 to the 1880 cohorts than from the 1880 to the 1890 cohorts. Although the means (medians) are illustrative only, couples who had all their births outside Tasmania had fewer children on average than other couples and their fertility fell from the 1860 to the 1870 cohorts onwards.

Table 6.11 Mean and median numbers of children by location of family births, complete group: 1860, 1870, 1880 and 1890 marriage cohorts, Tasmania

\begin{tabular}{|l|r|r|r|r|}
\hline Marriage cohort & 1860 & 1870 & 1880 & 1890 \\
\hline Type of location of family births & \multicolumn{4}{|c|}{ Mean } \\
\hline All births in Tasmania & 7.69 & 8.03 & 7.22 & 5.65 \\
\hline Births in Tasmania and elsewhere $^{\mid} 7.92$ & 8.61 & 6.35 & 5.95 \\
\hline All births outside Tasmania ${ }^{1}$ & 7.13 & 6.00 & 4.92 & 4.29 \\
\hline & \multicolumn{5}{|c|}{ Median } \\
\hline All births in Tasmania & 8 & 9 & 7 & 5 \\
\hline Births in Tasmania and elsewhere & 8 & 8 & 6 & 5 \\
\hline All births outside Tasmania & 8 & 5.5 & 5 & 4 \\
\hline
\end{tabular}

${ }^{1}$ Means are illustrative only, because of small numbers in this group - that is, in $1860, \mathrm{n}=$ 15 ; in 1870, $n=16$; in 1880, $n=12$; and in 1890, $n=21$. 


\section{Religion}

The relationship between religion and the number of children ever born is not very clear. Catholics had the highest mean (median) numbers of children in most marriage cohorts (Table 6.12). No other religious group consistently had the smallest mean (median) numbers of children, although Presbyterians and Other Nonconformists tended to have lower fertility than Anglicans and Methodists. The fall in fertility occurred later for Catholics than for the other religious groups. The mean (median) numbers of children fell from the 1880 cohort to the 1890 cohort for Catholics, while for Anglicans, Methodists and Other Nonconformists, fertility started to fall from the 1870 to the 1880 cohorts onwards. Fertility fell steadily for Presbyterians from the 1860 cohort to the 1890 cohorts. Methodists tended to have more children than the other Protestant groups and their fertility fell more slowly.

Table 6.12 Mean and median numbers of children by religion at marriage, complete group: 1860, 1870, 1880 and 1890 marriage cohorts, Tasmania

\begin{tabular}{|l|r|r|r|r|}
\hline Marriage cohort & 1860 & 1870 & 1880 & 1890 \\
\hline Type of religion & \multicolumn{4}{|c|}{ Mean } \\
\hline Anglican & 7.74 & 8.50 & 6.87 & 5.51 \\
\hline Catholic $^{1}$ & 8.28 & 7.44 & 8.00 & 6.36 \\
\hline Presbyterian & 7.95 & 6.97 & 6.22 & 5.27 \\
\hline Methodist & 7.97 & 8.37 & 7.57 & 6.21 \\
\hline Other Nonconformist & 7.51 & 7.62 & 6.73 & 5.12 \\
\hline & \multicolumn{5}{|c|}{ Median } \\
\hline Anglican & 8.0 & 9 & 7.0 & 5 \\
\hline Catholic & 8.5 & 8 & 8.5 & 6 \\
\hline Presbyterian/Church of Scotland & 8.0 & 7 & 6.0 & 5 \\
\hline Methodist & 8.0 & $8 / 9$ & 7.0 & 6 \\
\hline Other Nonconformist & 8.0 & 7 & 7.0 & 5 \\
\hline
\end{tabular}

${ }^{1}$ Means are illustrative only for 1870 because of the small number: $n=25$.

Note: Religion missing for one couple in the 1860 cohort. 


\section{Literacy}

In the analysis of literacy and fertility, I use data on whether the husband and/or wife signed the marriage certificate as an indicator of the husband and wife's literacy (Alter 1988). In examining mean (median) numbers of children by couples' literacy levels, I collapsed the categorisation used in Chapter 5 from four to two groups: both partners literate and husband and/or wife illiterate. This is because of small numbers in the illiterate groups, particularly in the two later cohorts.

In all marriage cohorts, the mean (median) numbers of children were considerably higher for couples where the husband and/or wife was illiterate compared with couples where both were literate, but the differences were much smaller for the 1890 cohort than for the earlier cohorts (Table 6.13). In the 1860 cohort, couples where the husband and/or wife was illiterate had a mean of 9 children (median 10), while the mean for couples where both were literate was 7.48 (median 8). By the 1890 cohort, the comparable means were 6 (median 6) for the illiterate group and 5.6 (median 5) for the literate group. Fertility fell for illiterate couples from the 1860 to the 1870 cohorts onwards and for literate couples from the 1870 to the 1880 cohorts onwards. For both literate and illiterate couples, the largest fall in fertility was from the 1880 to the 1890 cohorts.

Table 6.13 Mean and median numbers of children by parents' literacy, complete group: 1860, 1870, 1880 and 1890 marriage cohorts, Tasmania

\begin{tabular}{|l|r|r|r|r|}
\hline Marriage cohort & 1860 & 1870 & 1880 & 1890 \\
\hline Literacy type $^{|c|}$ Mean \\
\hline Husband and/or wife illiterate $^{1}$ & 9.00 & 8.47 & 8.05 & 6.00 \\
\hline Both husband and wife literate & 7.48 & 7.86 & 6.91 & 5.60 \\
\hline Literacy type $^{|5|}$ Median \\
\hline Husband and/or wife illiterate & 10 & 9 & 8 & 6 \\
\hline Both husband and wife literate & 8 & 8 & 7 & 5 \\
\hline
\end{tabular}

${ }^{1}$ Means are illustrative only for 1890 because of the small number in this group: $\mathrm{n}=27$. 


\section{Parity progression ratios}

In this final section, I examine parity progression ratios by marriage cohort and by three family characteristics that are important in relation to theories of fertility decline: socioeconomic status, type of geographic location and religion.

\section{Marriage cohorts}

Parity progression ratios - that is, the proportion of mothers at a given parity who went on to have another child-were fairly similar for mothers in the 1860 and 1870 cohorts (Table 6.14). However, parity progression ratios began to fall from the third to the fourth child onwards in the 1880 cohort and from the second to the third child onwards in the 1890 cohort. The largest percentage falls in progression between the 1870 and the 1880 cohorts were at parities five, nine and ten. For example, in the 1870 cohort, 93.5 per cent of those who had five children went on to have another child, whereas in the 1880 cohort, the corresponding proportion was 82.9 per cent. The differences in the percentage falls in parity progression ratios at low parities were larger between the 1880 and 1890 cohorts than between the 1870 and 1880 cohorts. For instance, 94.7 per cent of women in the 1870 cohort who had four children went on to have a fifth child, compared with 90.5 per cent of women in the 1880 cohort and 82.3 per cent in the 1890 cohort.

Table 6.14 Parity progression ratios, complete group: 1860, 1870, 1880 and 1890 marriage cohorts, Tasmania

\begin{tabular}{|l|c|c|c|c|}
\hline Marriage cohort & 1860 & 1870 & 1880 & 1890 \\
\hline Parity i & \multicolumn{3}{|c|}{ Parity } & progression ratios (i, i + 1) \\
\hline One & 0.9531 & 0.9541 & 0.9784 & 0.9528 \\
\hline Two & 0.9590 & 0.9593 & 0.9559 & 0.8950 \\
\hline Three & 0.9359 & 0.9382 & 0.9128 & 0.8496 \\
\hline Four & 0.9543 & 0.9465 & 0.9045 & 0.8229 \\
\hline Five & 0.9091 & 0.9348 & 0.8292 & 0.7373 \\
\hline Six & 0.8737 & 0.8930 & 0.8614 & 0.7940 \\
\hline Seven & 0.8675 & 0.8490 & 0.8043 & 0.7514 \\
\hline Eight & 0.7917 & 0.8221 & 0.7892 & 0.6906 \\
\hline Nine & 0.7895 & 0.7910 & 0.6575 & 0.6458 \\
\hline
\end{tabular}




\begin{tabular}{|l|r|r|r|r|}
\hline Marriage cohort & \multicolumn{1}{|c|}{1860} & \multicolumn{1}{|c|}{1870} & 1880 & \multicolumn{1}{c|}{1890} \\
\hline Parity i & \multicolumn{3}{|c|}{ Parity } & progression ratios (i, i + 1) \\
\hline Ten & 0.6667 & 0.6887 & 0.5729 & 0.7258 \\
\hline Eleven & 0.7167 & 0.6301 & 0.6364 & 0.4667 \\
\hline Twelve & 0.6047 & 0.5217 & 0.5429 & 0.4762 \\
\hline Thirteen & 0.3462 & 0.5417 & 0.6316 & 0.6000 \\
\hline Fourteen & 0.4444 & 0.4615 & 0.5833 & 0.6667 \\
\hline Fifteen & 0.0000 & 0.3333 & 0.1429 & 0.0000 \\
\hline Sixteen &.. & 0.0000 & 0.0000 &.. \\
\hline Total families (no.) & 256 & 283 & 417 & 529 \\
\hline
\end{tabular}

.. not applicable

Parity progression ratios can be used to calculate the percentage of mothers reaching each parity - that is, proportion of mothers having ' $i$ ' children $=$ proportion of mothers having ' $i-1$ ' children * parity progression ratio ' $i$. This is a useful way of measuring the fertility and changes in fertility of different groups.

The fertility levels of the 1860 and the 1870 cohorts were very similar, with very small differences in the proportions of women reaching each parity (Figure 6.2). For example, 85.6 per cent of women in the 1860 cohort had four or more children compared with 85.9 per cent in the 1870 cohort, while 56.3 per cent of the 1860 cohort had eight or more children compared with 57.6 per cent of the 1870 cohort.

Fertility fell from the 1870 cohort to the 1880 cohort and then to the 1890 cohort. From the 1870 to the 1880 cohorts, the proportions of women reaching each parity began to fall steadily after parity four. In the 1870 cohort, for instance, 76 per cent of mothers had six or more children, compared with 64 per cent of mothers in the 1880 cohort, while for those with 11 or more children, the proportions were 25.8 per cent and 13.2 per cent, respectively.

There was a much larger fall in fertility from the 1880 to the 1890 cohorts, with the proportion of women reaching each parity dropping sharply after parity two. In the 1880 cohort, 85.4 per cent of mothers had four or more children compared with 72.5 per cent in the 1890 cohort, while 35 per cent of mothers in the 1880 cohort had nine or more children compared with 18.1 per cent in the 1890 cohort. 


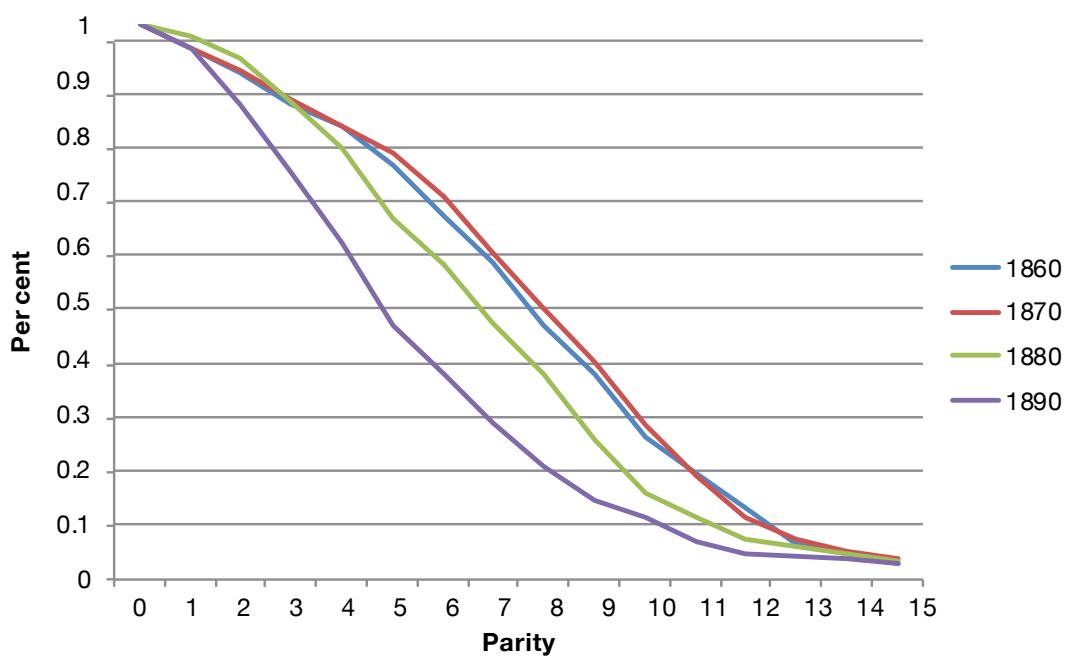

Figure 6.2 Proportions of women reaching each parity, complete group: 1860, 1870, 1880 and 1890 marriage cohorts, Tasmania

Source: Author's calculations.

Since the proportions of mothers reaching each parity were very similar in the 1860 and 1870 cohorts and the numbers in each cohort are considerably smaller than in the other two cohorts, these cohorts are combined in the fertility analysis that follows.

For each characteristic - socioeconomic status, geographic location and religion-the following analysis compares the proportion of mothers reaching each parity by the various groups for each marriage cohort, then looks at trends for each group across the marriage cohorts.

\section{Socioeconomic status}

Examining the proportion of mothers reaching each parity by husband's socioeconomic status shows differences in fertility among the various socioeconomic groups within each marriage cohort (Figure 6.3). In the $1860 / 70$ cohorts, white-collar workers had the lowest fertility while farmers and unskilled workers had the highest. The largest differences in the proportions of women reaching each parity were between the whitecollar, skilled and lower-skilled workers, on the one hand, and farmers and unskilled workers on the other. For instance, 69.2 per cent of whitecollar workers had five or more children, compared with 76.2 per cent of skilled workers, 76.9 per cent of lower-skilled workers, 86.9 per cent of unskilled workers and 88.7 per cent of farmers. 


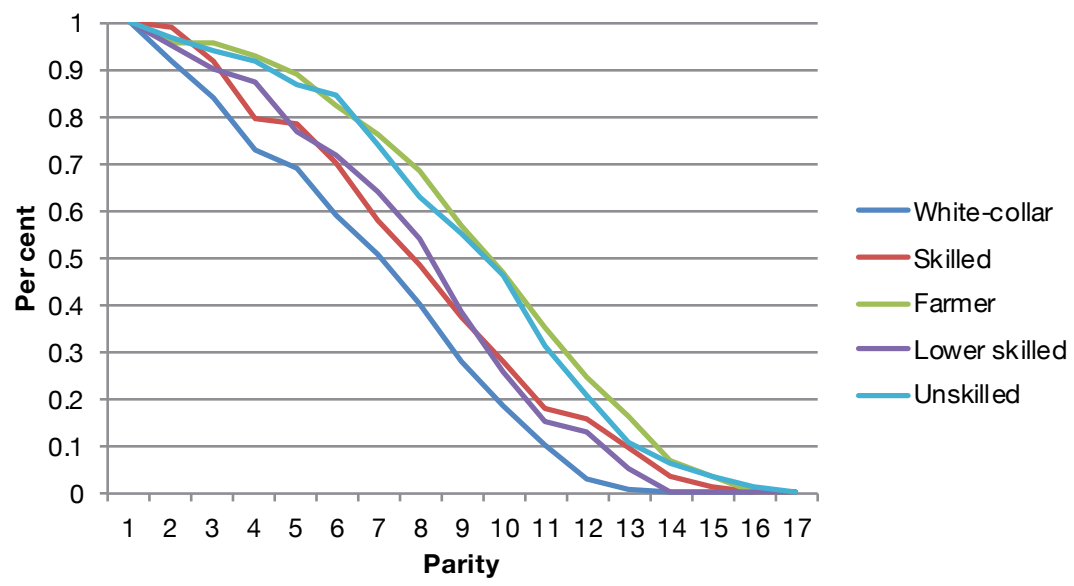

Figure 6.3 Proportions of women reaching each parity by socioeconomic status, complete group: 1860/70 marriage cohorts, Tasmania

Source: Author's calculations.

White-collar workers again had the lowest fertility in the 1880 cohort, but their fertility was substantially lower than the other four groups of workers (Figure 6.4). The fertility levels of farmers and unskilled workers were closer to those of the skilled and lower-skilled workers than in the earlier cohorts. The proportion of women in white-collar couples reaching parities higher than five was much smaller than for other groups. Only 45.4 per cent of white-collar couples had six or more children, compared with 57.7 per cent of skilled workers, 77.4 per cent of lower-skilled workers, 79.3 per cent of unskilled workers and 83.2 per cent of farmers.

White-collar workers still had the lowest fertility in the 1890 cohort, but the largest differences were between the white-collar, skilled and lower-skilled workers, on the one hand, and the farmers and unskilled workers on the other, particularly at higher parities (Figure 6.5). The proportions of farmers and unskilled workers with eight or more children, for instance, were more than double those of white-collar, skilled and unskilled workers: 43.5 per cent of farmers and 38.2 per cent of unskilled workers had eight or more children, compared with 9.3 per cent of white-collar workers, 14.1 per cent of skilled workers and 17.6 per cent of lower-skilled workers. 


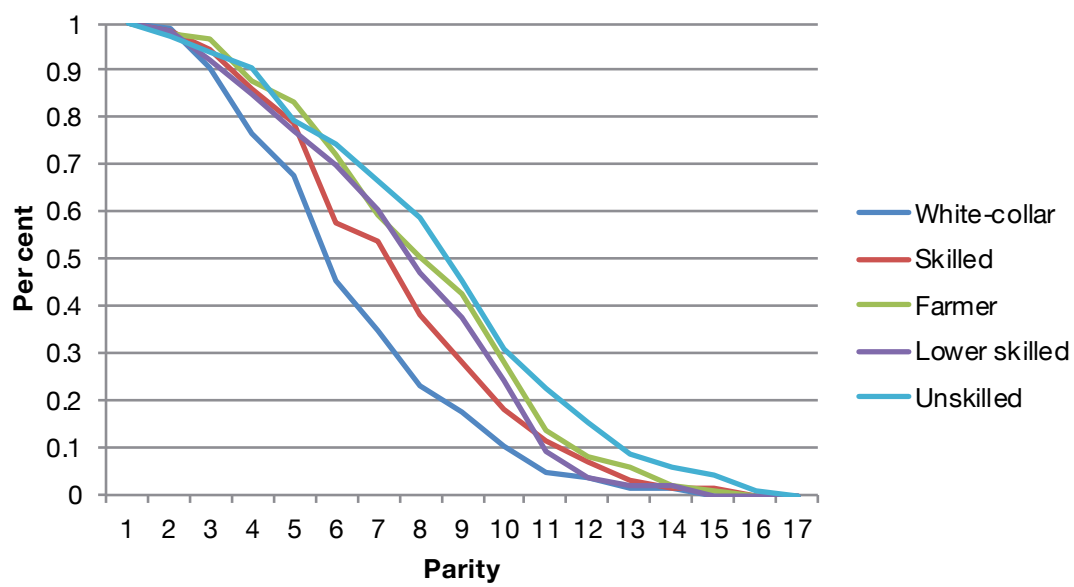

Figure 6.4 Proportions of women reaching each parity by socioeconomic status, complete group: 1880 marriage cohort, Tasmania Source: Author's calculations.

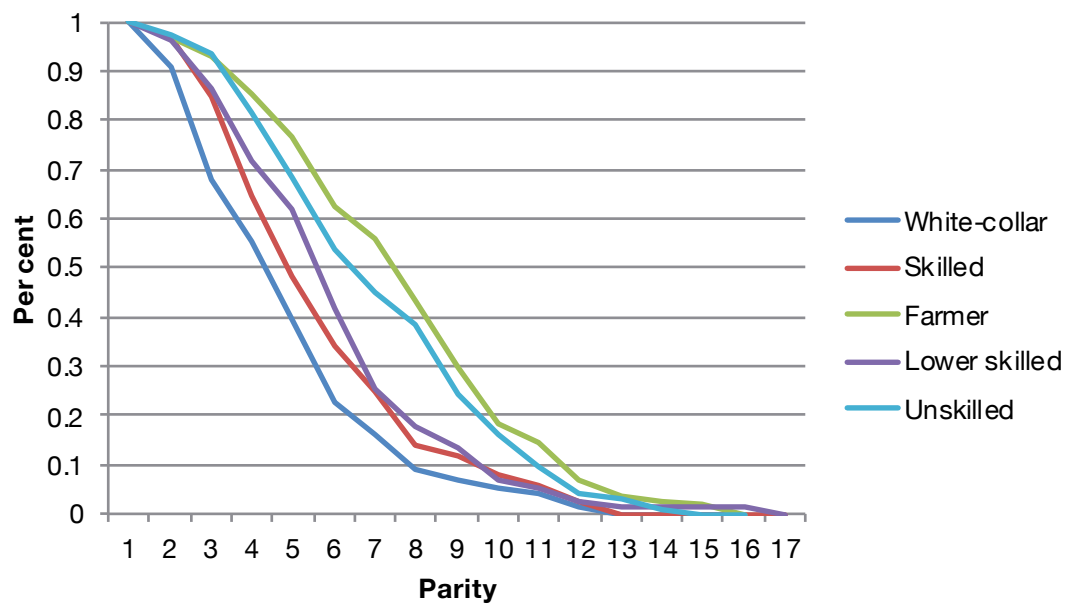

Figure 6.5 Proportions of women reaching each parity by socioeconomic status, complete group: 1890 marriage cohort, Tasmania

Source: Author's calculations. 
Fertility fell for white-collar workers from the $1860 / 70$ cohorts to the 1880 cohort (Figure 6.6). While the 1880 cohort had a somewhat higher proportion of women reaching the lower parities than the 1860/70 cohorts, the proportion of women at each parity fell steadily after the fifth. Fertility also fell between the 1880 and 1890 cohorts, with the proportions of mothers reaching each parity falling after parity one and falling sharply after parity two.

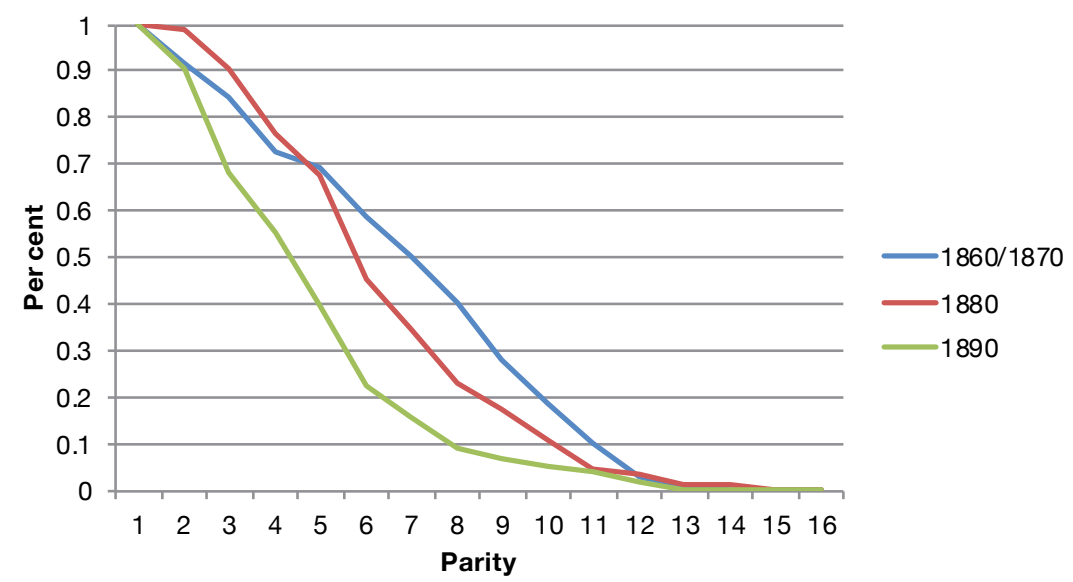

Figure 6.6 White-collar workers, proportions of women reaching each parity, complete group: 1860/70, 1880 and 1890 marriage cohorts, Tasmania

Source: Author's calculations.

Fertility fell somewhat for skilled workers from the 1860/70 cohorts to the 1880 cohort (Figure 6.7), with the proportion of women reaching each parity falling after parity five. The fall in fertility was much more substantial between the 1880 and the 1890 cohorts, with the proportions of women at each parity falling sharply after parity two. 


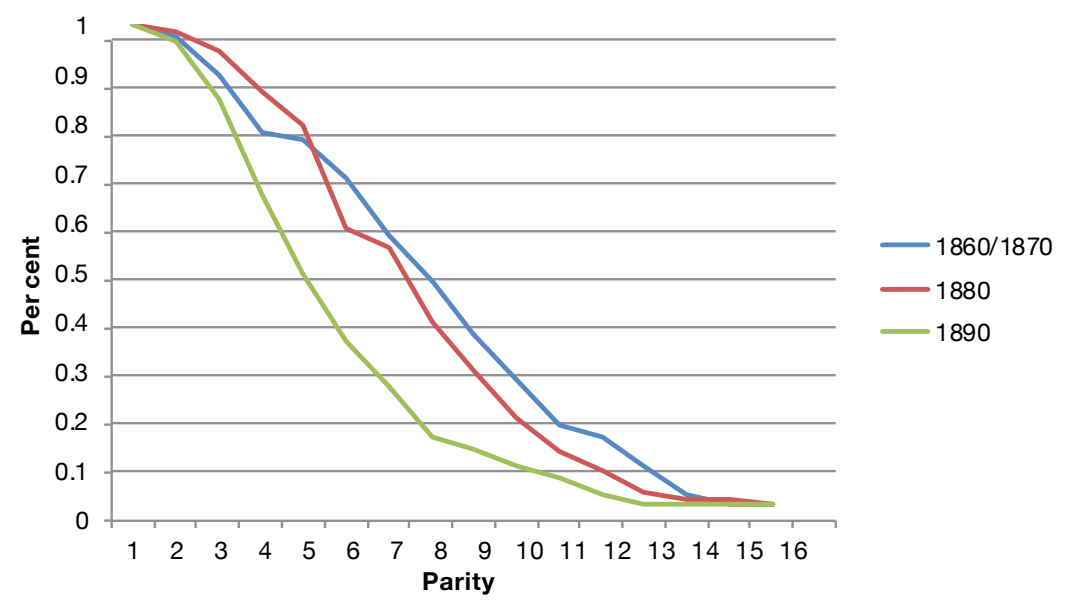

Figure 6.7 Skilled workers, proportions of women reaching each parity, complete group: 1860/70, 1880 and 1890 marriage cohorts, Tasmania Source: Author's calculations.

In contrast, there was a substantial fall in the fertility of farmers' wives between the 1860/70 cohorts and the 1880 cohort (Figure 6.8). The proportion of women reaching each parity began to fall after parity three, but the differences were not large until after the sixth parity. Fertility also fell from the 1880 to the 1890 cohorts after parity four, but the differences in the proportions reaching each parity were not as large as between the earlier cohorts.

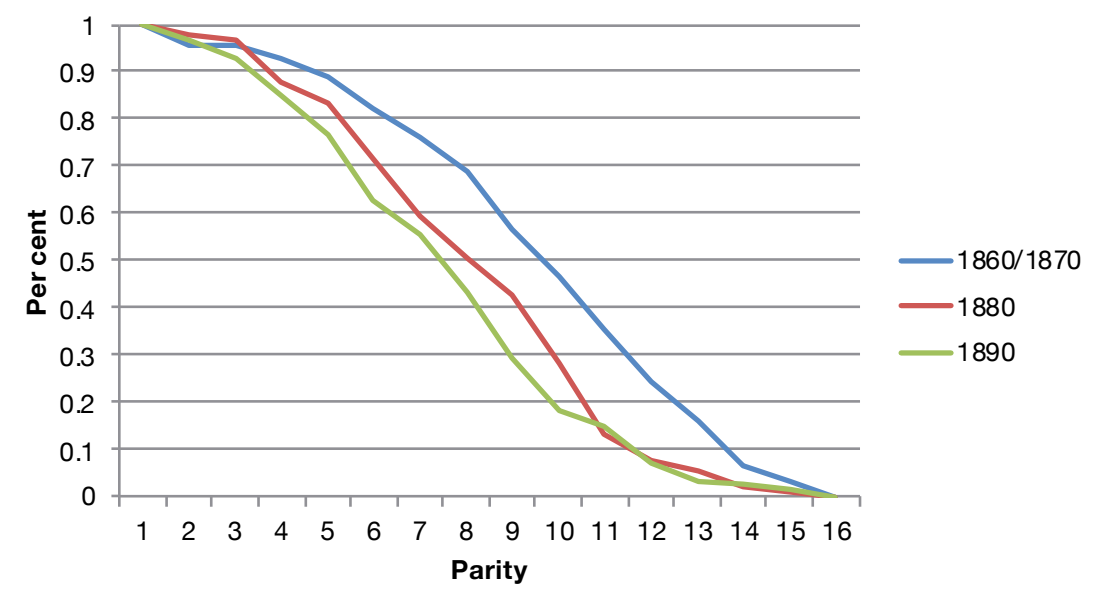

Figure 6.8 Farmers, proportions of women reaching each parity, complete group: 1860/70, 1880 and 1890 marriage cohorts, Tasmania Source: Author's calculations. 
The fertility levels of lower-skilled workers were very similar in the $1860 / 70$ and 1880 cohorts, except for a fall in the proportions of women reaching very high parities in the 1880 cohort - that is, after parity 10 (Figure 6.9). Fertility fell markedly between the 1880 and 1890 cohorts, with the proportions of lower-skilled workers' wives reaching each parity dropping sharply after parity two.

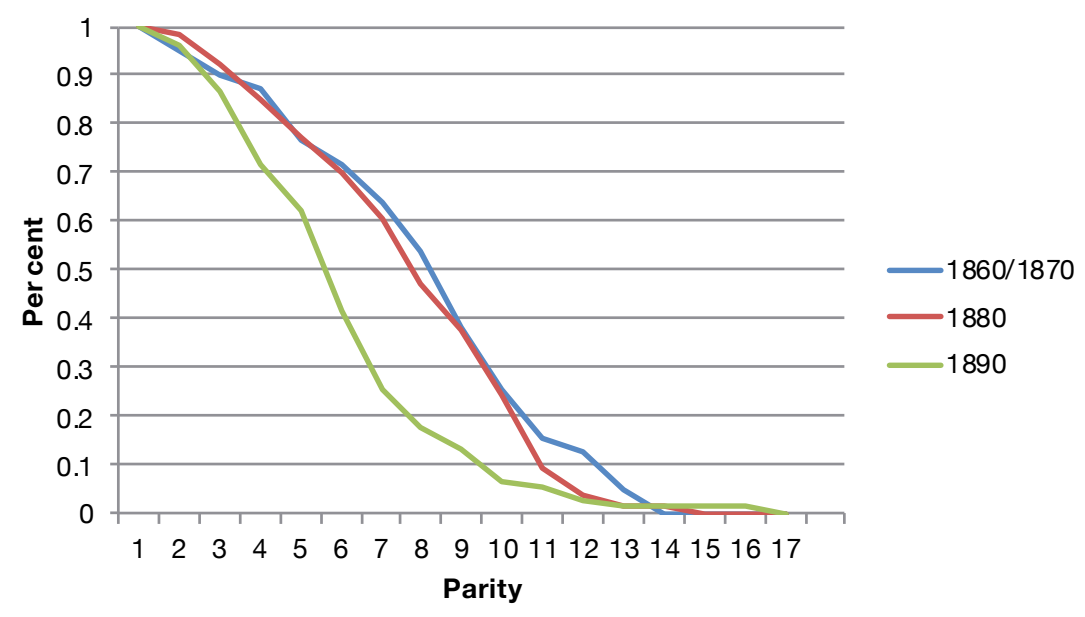

Figure 6.9 Lower-skilled workers, proportions of women reaching each parity, complete group: 1860/70, 1880 and 1890 marriage cohorts, Tasmania

Source: Author's calculations.

The large fall between the 1880 and 1890 cohorts may be related to changes in the composition of the lower-skilled group, with the 1890 cohort including men in the more 'modern' occupations of 'engine driver' and 'fireman-gas works'.

Fertility fell for unskilled workers between the 1860/70 and 1880 cohorts, with the proportion reaching each parity falling after parity four (Figure 6.10). The fall in fertility was much larger between the 1880 and the 1890 cohorts and occurred after parity three. 


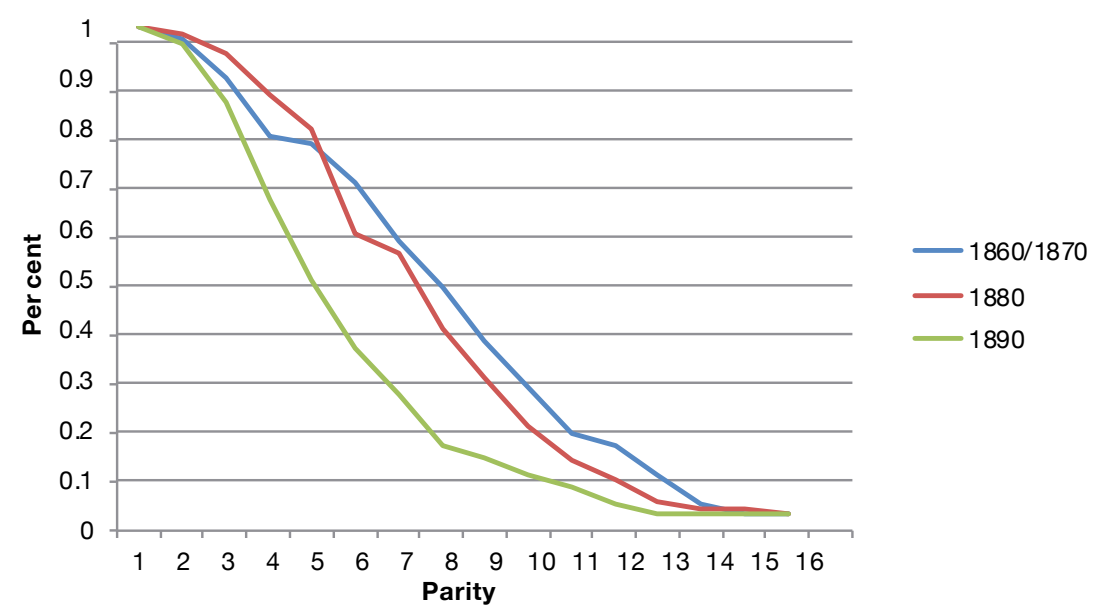

Figure 6.10 Unskilled workers, proportions of women reaching each parity, complete group: 1860/70, 1880 and 1890 marriage cohorts, Tasmania Source: Author's calculations.

\section{Type of geographic location}

Women having their first birth outside Tasmania are excluded from this analysis because of the small numbers in the group.

In the $1860 / 70$ cohorts, the proportions of women reaching each parity were lower for those living in urban areas than for those in rural areas at every parity after parity one, with the differences being greater at higher parities (Figure 6.11). The proportion of women in rural areas with four or more children was 90.7 per cent compared with 79.4 per cent for women in urban areas, while the proportions with nine or more were 56.2 per cent and 33.7 per cent, respectively. Urban women had a maximum of 15 children compared with 16 for rural women. 


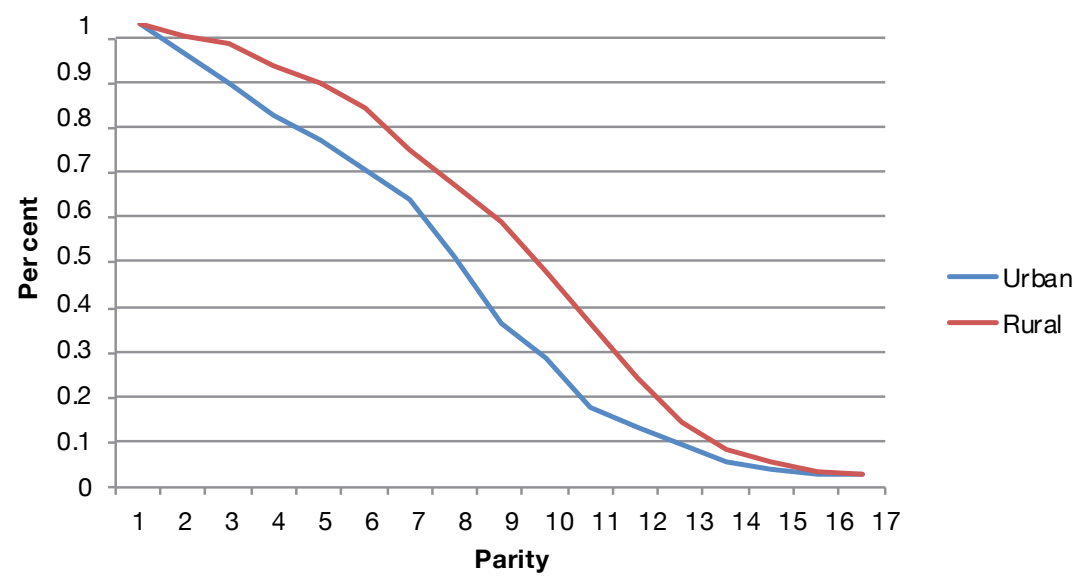

Figure 6.11 Proportions of women reaching each parity by urban/rural location, complete group: 1860/70 marriage cohorts, Tasmania Source: Author's calculations.

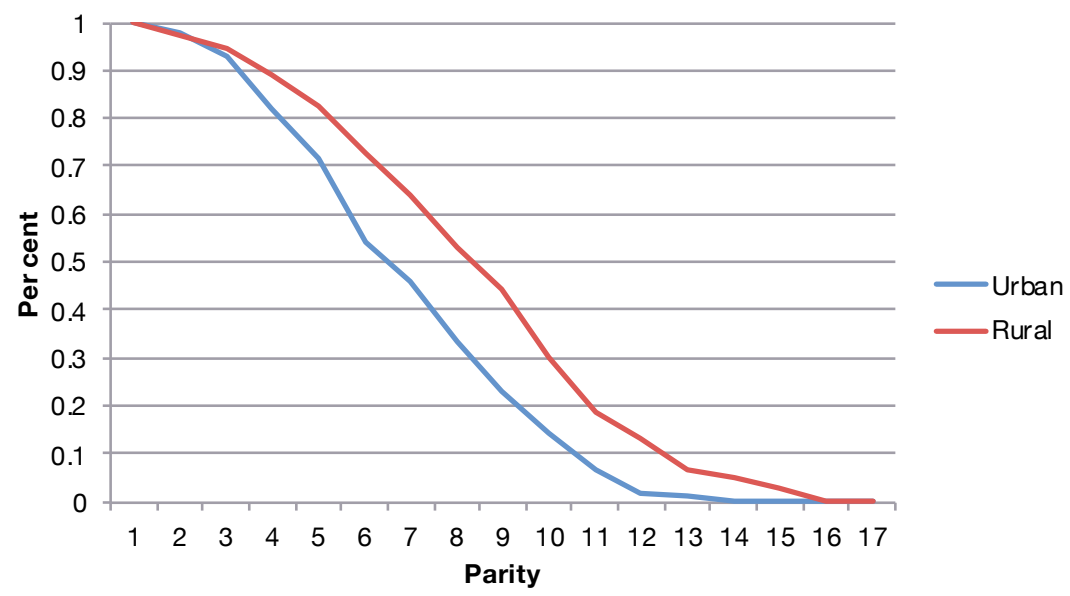

Figure 6.12 Proportions of women reaching each parity by urban/rural location, complete group: 1880 marriage cohort, Tasmania

Source: Author's calculations.

The fertility of urban women was also substantially lower than that of rural women in the 1880 cohort, although the proportions reaching each parity were similar up to parity three (Figure 6.12). As with the 1860/70 cohorts, the differences between urban and rural women's fertility were larger at higher parities. The proportion of rural women with four or 
more children was 88.9 per cent compared with 81.9 per cent for urban women, but the corresponding proportions for women with eight or more children were 53.3 per cent and 33.5 per cent, respectively. The maximum number of children fell to 13 for urban women but remained at 16 for rural women.

These trends continued in the 1890 cohort, with the proportions reaching each parity being lower for urban women than for rural women at every parity after parity one (Figure 6.13). In this cohort, however, the differences between the two groups were substantial at both low and high parities. For example, 90.6 per cent of rural women had three or more children compared with 79.4 per cent of urban women, while 24.4 per cent of rural women had nine or more compared with 10 per cent of urban women. The maximum number of children for rural woman remained at 16, while the maximum for urban women fell to 12 .

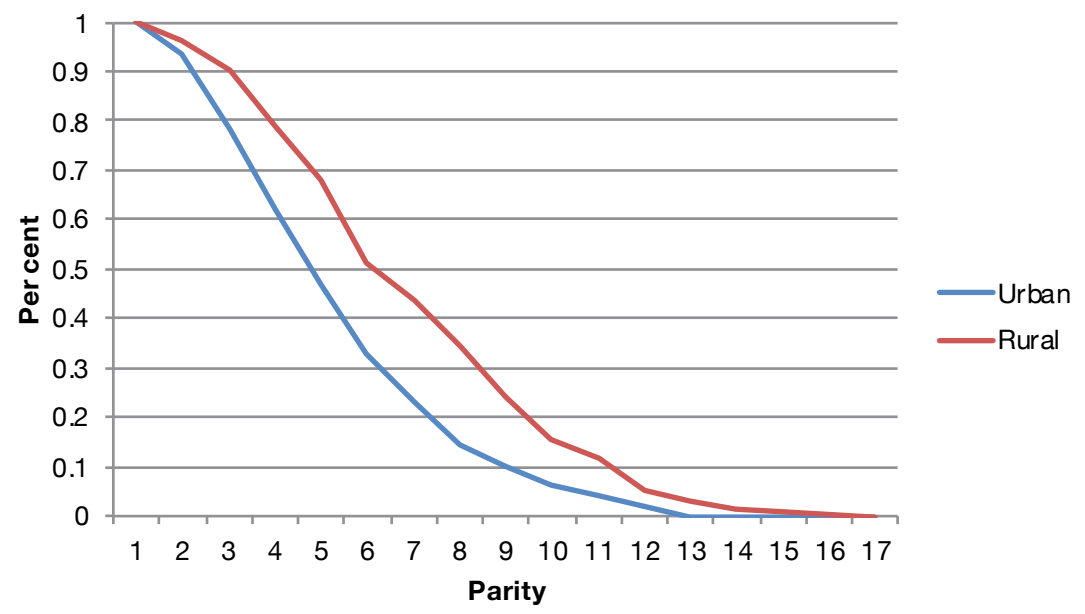

Figure 6.13 Proportions of women reaching each parity by urban/rural location, complete group: 1890 marriage cohort, Tasmania

Source: Author's calculations.

Fertility fell for urban women between the $1860 / 70$ cohorts and the 1880 cohort (Figure 6.14). The proportions of women reaching each parity were slightly higher at low parities for the 1880 cohort compared with the $1860 / 70$ cohorts, but they began to fall steadily after parity four. 
There was a larger fall in fertility for urban women from the 1880 to the 1890 cohorts. Falls in the proportions of women reaching each parity were much larger between these two cohorts than the previous cohorts and occurred after parity one, with a sharp fall after parity two.

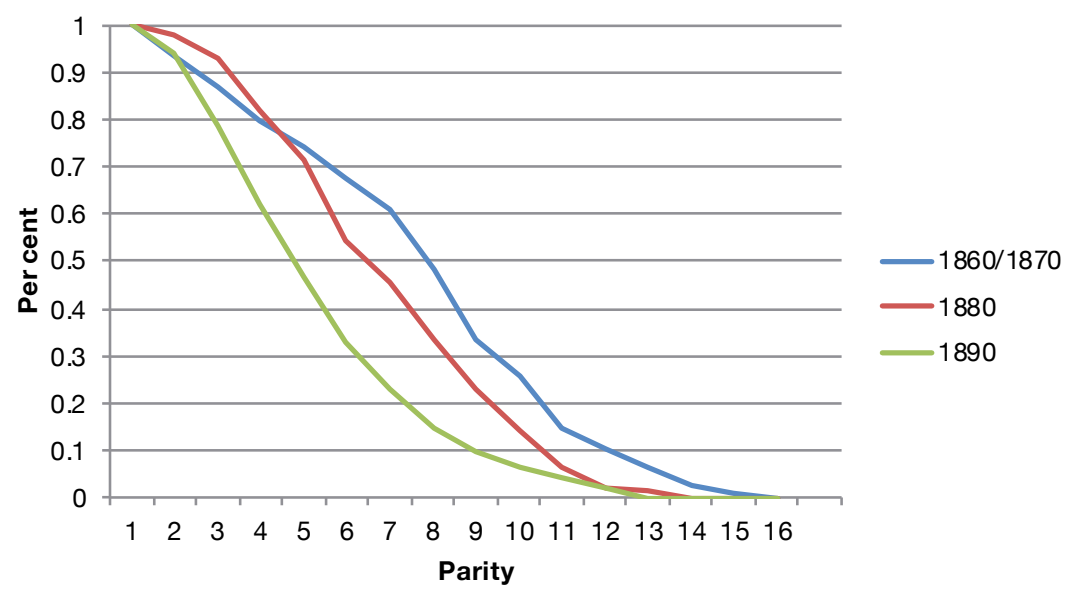

Figure 6.14 Proportions of women reaching each parity for couples living in an urban area, complete group: 1860/70, 1880 and 1890 marriage cohorts, Tasmania

Source: Author's calculations.

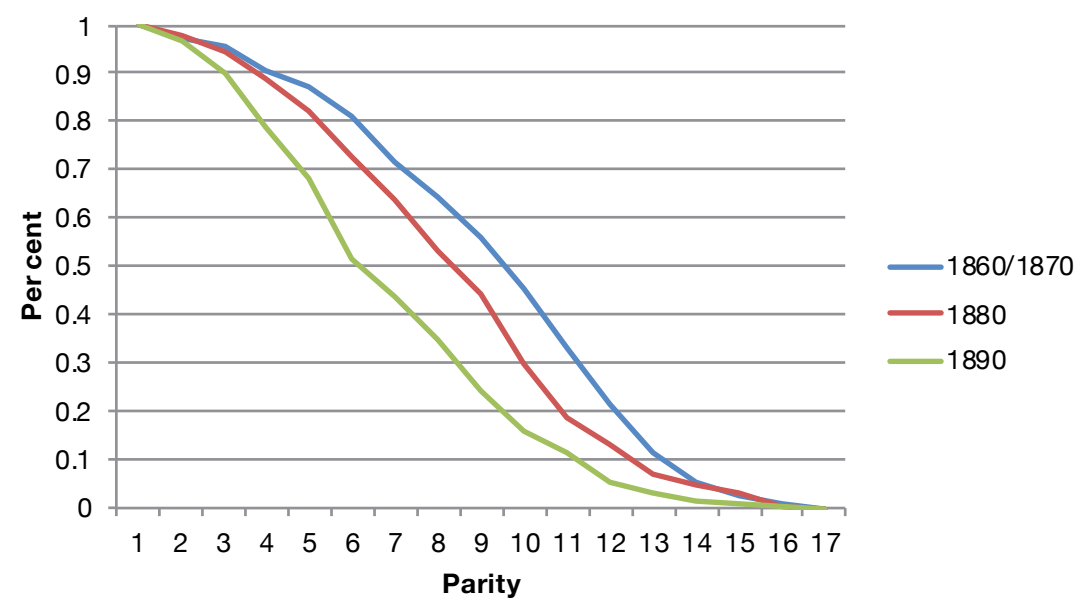

Figure 6.15 Proportions of women reaching each parity for couples living in a rural area, complete group: 1860/70, 1880 and 1890 marriage cohorts, Tasmania 
Fertility also fell for women in rural areas from the $1860 / 70$ cohorts to the 1880 cohort, with the proportions of women reaching each parity falling steadily after parity four (Figure 6.15). There was a more substantial fall in fertility between the 1880 and 1890 cohorts, with the proportion of rural women reaching each parity falling steadily after parity two.

\section{Religion}

There were no clear differences in the fertility of the various religious groups in the 1860/70 cohorts, although Other Nonconformists and Presbyterians tended to have lower proportions of women reaching each parity than other groups (Figure 6.16). Among Other Nonconformists, for instance, 69.7 per cent had five or more children, compared with 71.9 per cent of Presbyterians, 76.1 per cent of Methodists, 77 per cent of Anglicans and 80.4 per cent of Catholics.

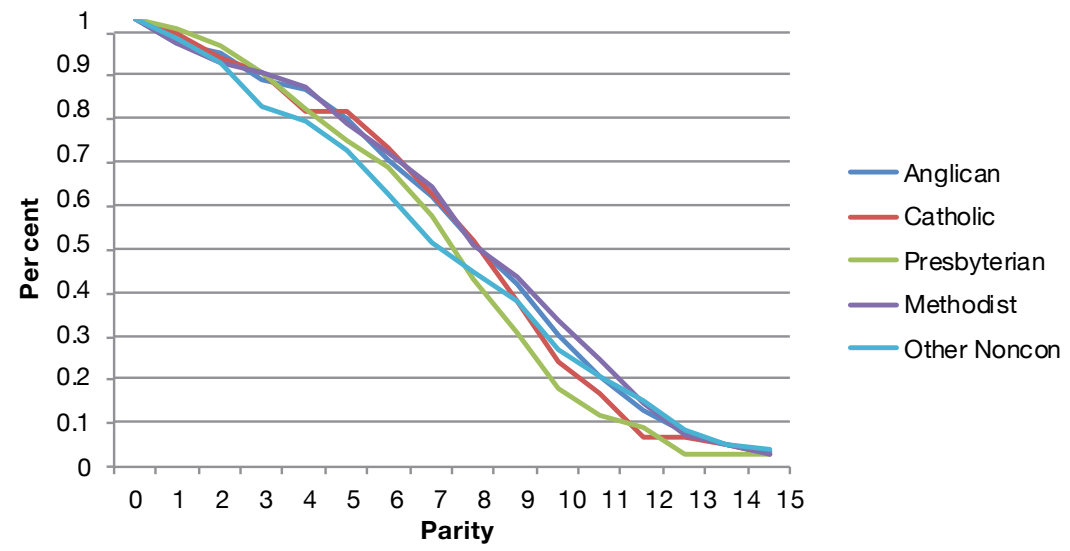

Figure 6.16 Proportions of women reaching each parity by religion, complete group: 1860/70 marriage cohorts, Tasmania

Source: Author's calculations.

Catholic fertility was substantially higher than that of other religious groups in the 1880 cohort, while Methodist fertility tended to be higher than that of other Protestant groups (Figure 6.17). Presbyterians tended to have the lowest fertility, although the proportions of women reaching higher parities were similar to those of Other Nonconformists. At lower parities, for instance, 78.4 per cent of Catholics had five or more children compared with 71.1 per cent of Methodists, 65.8 per cent of Other Nonconformists, 56.8 per cent of Anglicans and 53.7 per cent 
of Presbyterians. At higher parities, 25.5 per cent of Catholics had 10 or more children, compared with 18.6 per cent of Methodists, 12.2 per cent of Anglicans, 6.6 per cent of Other Nonconformists and 3.7 per cent of Presbyterians.

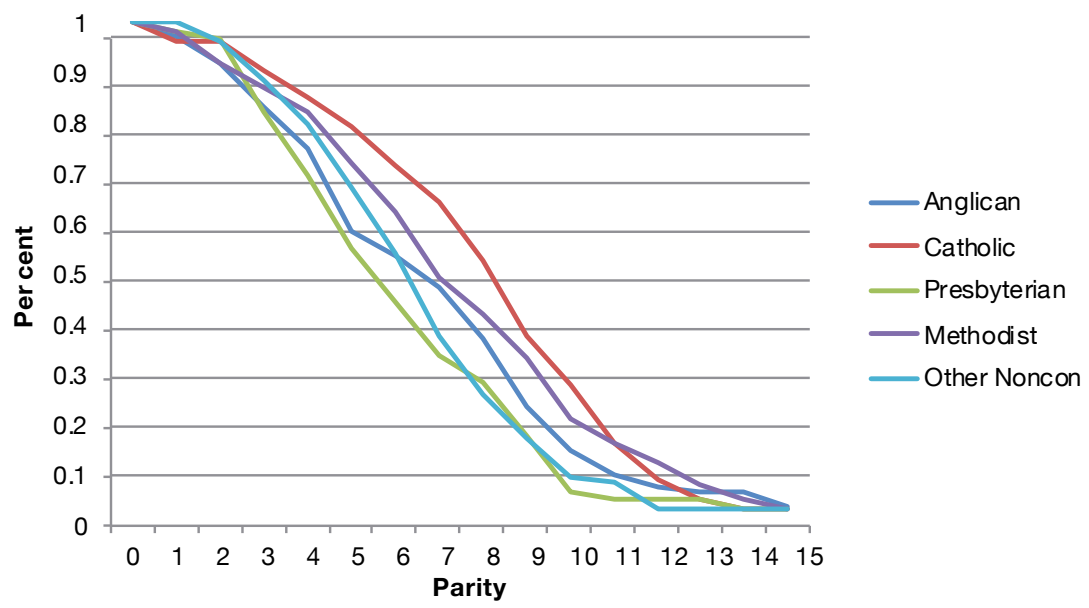

Figure 6.17 Proportions of women reaching each parity by religion, complete group: 1880 marriage cohort, Tasmania

Source: Author's calculations.

In the 1890 cohort, Catholics again had the highest fertility and Presbyterians and Other Nonconformists the lowest, with the proportions of Presbyterians and Other Nonconformists reaching each parity virtually identical at most parities (Figure 6.18). The proportions of Methodists reaching each parity were very similar to those of Catholics between parities five and seven. For instance, 70.1 per cent of Methodists and 69.8 per cent of Catholics had five or more children compared with 57.1 per cent of Anglicans, 52.4 per cent of Presbyterians and 52.3 per cent of Other Nonconformists. However, the proportion of Catholics with 10 or more children was higher than for other groups, at 18.9 per cent, compared with 13.7 per cent of Methodists, 10.1 per cent of Anglicans, 9.5 per cent of Presbyterians and 9.3 per cent of Other Nonconformists. 


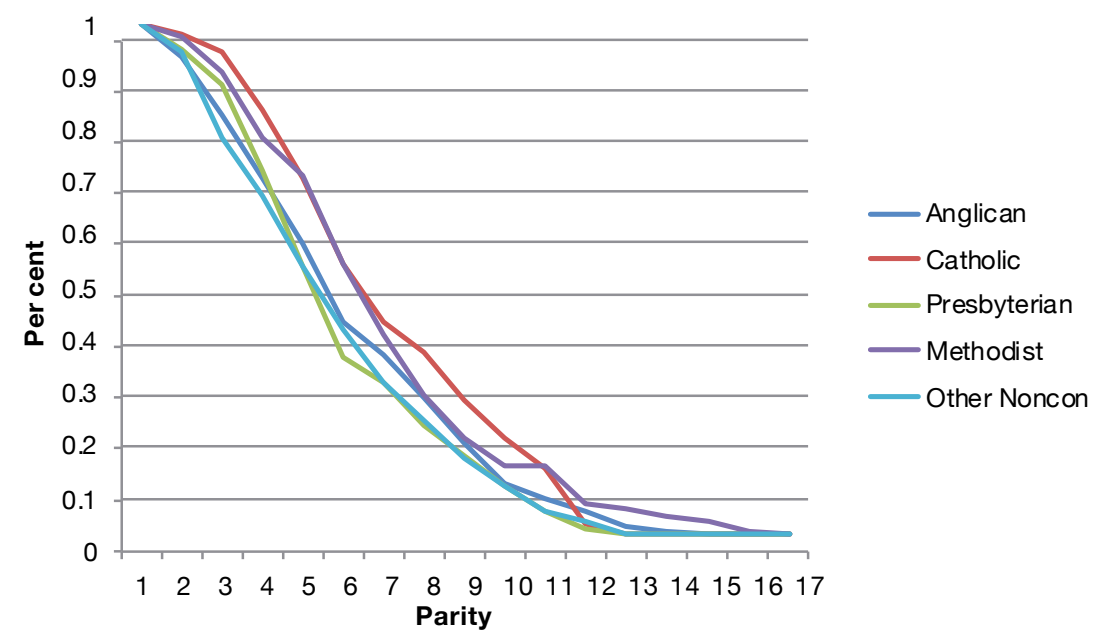

Figure 6.18 Proportions of women reaching each parity by religion, complete group: 1890 marriage cohort, Tasmania

Source: Author's calculations.

Fertility fell markedly for Anglicans from the $1860 / 70$ cohorts to the 1880 cohort, with the proportion of women reaching each parity falling after parity three (Figure 6.19). Fertility also fell substantially in the 1890 cohort after parity one. The percentage differences between the 1880 and 1890 cohorts were higher at lower parities and lower at higher parities, compared with the differences between the 1860/70 cohorts and the 1880 cohort.

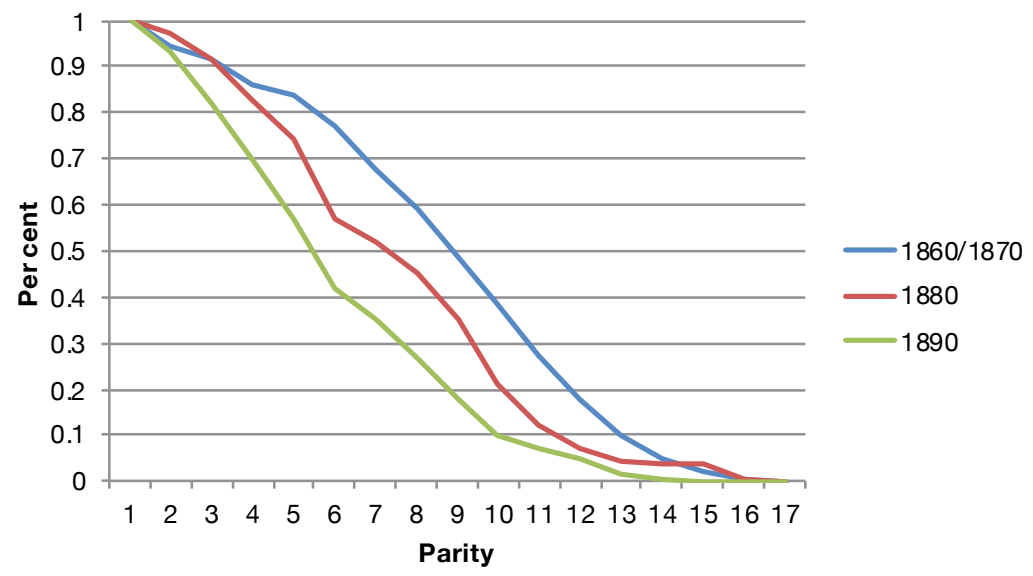

Figure 6.19 Anglicans, proportions of women reaching each parity, complete group: 1860/70, 1880 and 1890 marriage cohorts, Tasmania Source: Author's calculations. 
The fertility levels of Catholic women in the $1860 / 70$ and 1880 cohorts were very similar, although the proportions of women reaching each parity were slightly higher in the 1880 cohort at some lower and some higher parities (Figure 6.20). Fertility fell substantially from the 1880 to the 1890 cohorts, with the proportion of Catholic women reaching each parity falling sharply after parity three.

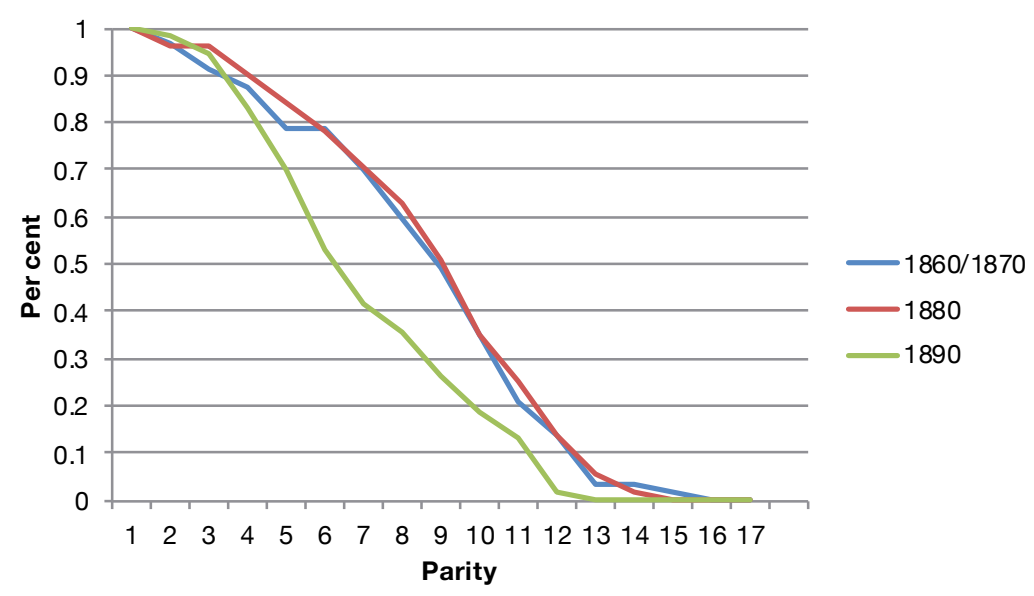

Figure 6.20 Catholics, proportions of women reaching each parity, complete group: 1860/70, 1880 and 1890 marriage cohorts, Tasmania Source: Author's calculations.

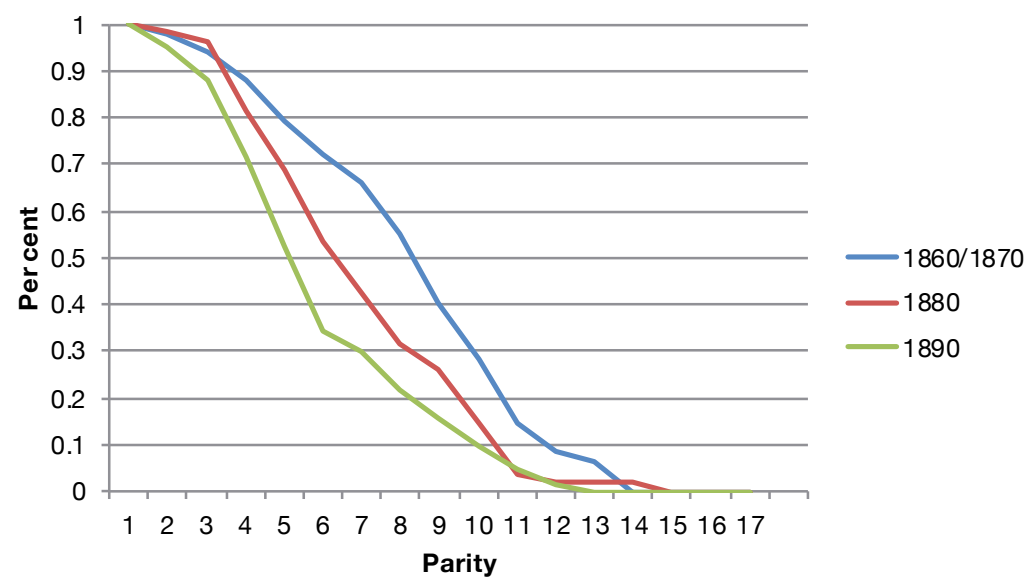

Figure 6.21 Presbyterians, proportions of women reaching each parity, complete group: 1860/70, 1880 and 1890 marriage cohorts, Tasmania Source: Author's calculations. 
Fertility fell for Presbyterians from the $1860 / 70$ cohorts to the 1880 cohort, with the proportion of Presbyterian women reaching each parity falling sharply after parity three (Figure 6.21). The fall in fertility from the 1880 to the 1890 cohorts was not as large, but occurred after parity one, with steep falls between parities three and seven.

The fertility of Methodist women also fell from the 1860/70 cohorts to the 1880 cohort, although the falls were not as large as for Presbyterian or Anglican women (Figure 6.22). There was a steady fall in the proportion of women reaching each parity after parity four. The fall in fertility from the 1880 to the 1890 cohorts was much larger and occurred after parity three. In the 1860/70 cohorts, there were slightly higher proportions of Methodist women reaching the lowest parities-parities two and threethan in the two later cohorts.

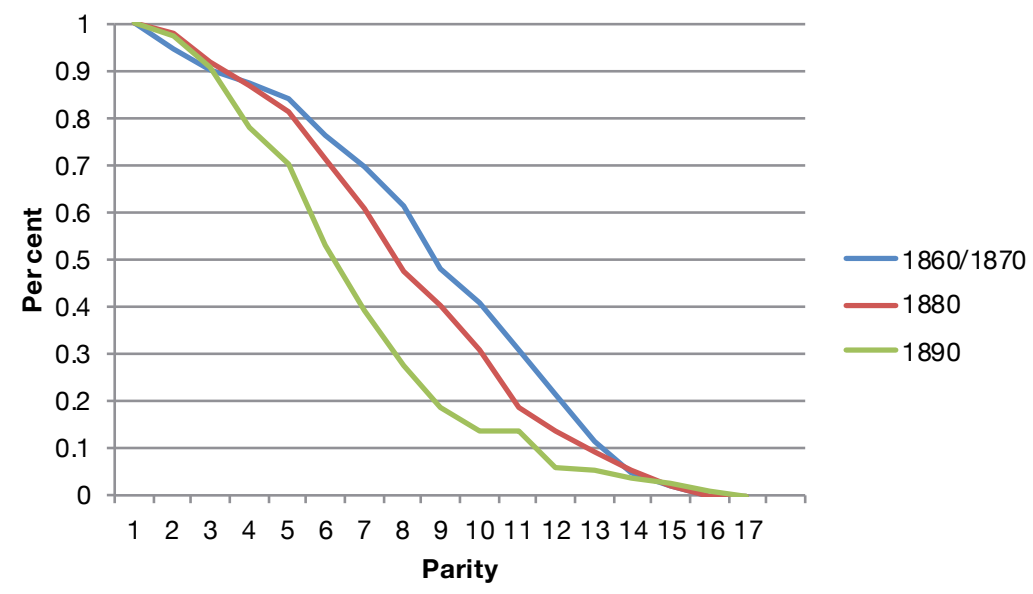

Figure 6.22 Methodists, proportions of women reaching each parity, complete group: 1860/70, 1880 and 1890 marriage cohorts, Tasmania Source: Author's calculations.

Other Nonconformists' fertility also fell from the 1860/70 cohorts to the 1880 cohort, with the proportion of women reaching each parity falling sharply after parity five (Figure 6.23). The proportions of women reaching lower parities, however, were higher in the 1880 cohort than the $1860 / 70$ cohorts. There was a large fall in fertility from the 1880 to the 1890 cohorts from parity two onwards. For women at higher parities, the falls were smaller between the 1880 and 1890 cohorts than between the two earlier cohorts. 


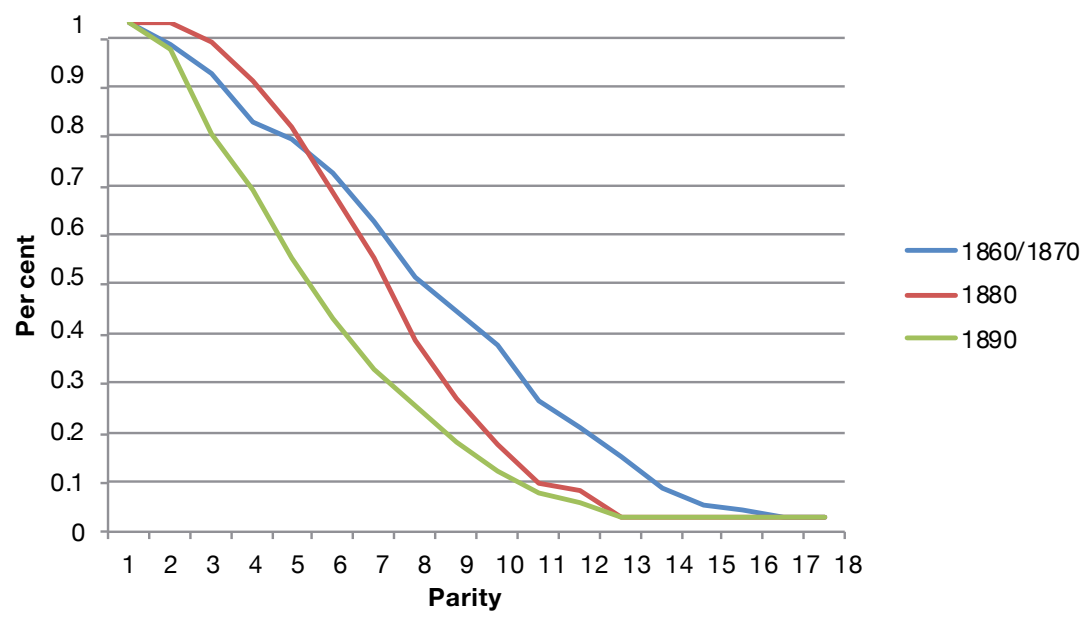

Figure 6.23 Other Nonconformists, proportions of women reaching each parity, complete group: 1860/70, 1880 and 1890 marriage cohorts, Tasmania

Source: Author's calculations.

\section{Discussion}

Bivariate analyses of the mean (median) numbers of children ever born and of parity progression ratios for the complete group in the four Tasmanian marriage cohorts provide support for some of the theories of why fertility declined in the late 19th century.

Fertility declined in Tasmania from the second half of the 1880s. Fertility began to fall from the $1860 / 70$ cohorts to the 1880 cohort but there was a much larger fall from the 1880 to the 1890 cohorts. In the 1880 cohort, fertility fell steadily after parity four, while in the 1890 cohort it dropped sharply after parity two. This supports demographic transition theory, since the 1880s and 1890s were a period of social and economic change and modernisation in Tasmania. This will be expanded on in the qualitative analysis chapter.

There were marked differences in the fertility decline by socioeconomic status, supporting theories of diffusion and economic theories. Whitecollar workers had lower fertility than all other workers in the 1860/70 cohorts, well before fertility declined in general, indicating that they were the earliest group to control their fertility. The timing of the fertility decline also varied among socioeconomic groups. For white-collar 
workers, fertility fell across all marriage cohorts, while for skilled, lowerskilled and unskilled workers, fertility fell from the 1880 to the 1890 cohorts. The timing of the fertility decline for farmers was different, with a large fall in fertility between the $1860 / 70$ and 1880 cohorts and a much lower fall between the 1880 and 1890 cohorts. One reason for the large difference in fertility of farmers in the $1860 / 70$ and 1880 cohorts may be related to differences in the composition of the two groups, with farmers in the $1860 / 70$ cohorts more likely to be 'selectors', many of whom failed at farming, while those in the 1880 cohort may have been more successful farmers.

As noted, the bivariate analysis of trends in fertility for different socioeconomic status groups uses husband's occupation at the birth of the first child as the measure of socioeconomic status. Since a relatively high proportion of men changed their socioeconomic status at some time during their wife's childbearing years (Table 5.11), the multivariate analysis, which measures socioeconomic status at the birth of each specific child, will provide a clearer picture of the relationship between socioeconomic status and fertility decline.

There were also marked differences in the fertility decline by urban/rural location, supporting theories of diffusion. Fertility was lower for urban women than for rural women in the $1860 / 70$ cohorts, indicating that they were already controlling their fertility. Fertility fell for both urban and rural women from the $1860 / 70$ cohorts to the 1880 cohort and then to the 1890 cohort. The fall between the 1880 and 1890 cohorts was more substantial than the fall between the $1860 / 70$ and 1880 cohorts. This mirrors the trend in the fertility decline for the complete group as a whole.

Differences in fertility between the religious groups were not very clear and do not provide strong support for secularisation theory. Catholics tended to have higher fertility than other groups, while Presbyterians and Other Nonconformists tended to have lower fertility. Methodists tended to have higher fertility than all other Protestant groups. Fertility fell later for Catholics than the other religious groups, falling from the 1880 to the 1890 cohorts for Catholics and from the 1860/70 cohorts for all other groups. 
This text is taken from Australia's Fertility Transition: A study of 19th-century Tasmania, by Helen Moyle, published 2020 by ANU Press, The Australian National University, Canberra, Australia.

doi.org/10.22459/AFT.2020.06 